\title{
Stereochemistry of Acrylate Polymerization in Toluene Using $n$-BuLi
}

\author{
Weihong LiU, ${ }^{\dagger}$ Tamaki NaKano, ${ }^{*}$ and Yoshio OKamoto ${ }^{*, \dagger}$ \\ Joint Research Center for Precision Polymerization (JRCPP)-Japan Chemical Innovation Institute (JCII), \\ Graduate School of Engineering, Nagoya University, Chikusa-ku, Nagoya 464-8603, Japan \\ * Department of Applied Chemistry, Graduate School of Engineering, Nagoya University, \\ Chikusa-ku, Nagoya 464-8603, Japan
}

(Received November 18, 1998) KEY WORDS Anionic Polymerization / Tacticity / Acrylate / Methacrylate / Lithium Hydroxide /
Stereospecific Polymerization /

The stereostructure of a vinyl polymer often significantly affects its physical and chemical properties. Therefore, stereocontrol of vinyl polymerizations is an important topic in macromolecular science, and various stereospecific polymerizations using Ziegler-Natta, metallocene, or anionic catalysts (initiators) have been examined. ${ }^{1,2}$ As to anionic polymerization, methacrylate polymerization has been most systematically investigated, and both highly isotactic and syndiotactic polymers have been synthesized. ${ }^{2,3}$ However, the stereocontrol of acrylate polymerization is generally difficult probably because of the absence of the $\alpha$-methyl group which may greatly contribute to the formation of a propagation center with a high stereospecificity. ${ }^{2,4}$

In this work, we investigated the effects of the basic conditions (temperature and concentration) on the stereochemistry of the anionic polymerization of methyl and $t$-butyl acrylates (MA and tBA) with toluene and $n$-BuLi which are often used as a solvent and an initiator, respectively, for the anionic polymerization of methacrylic monomers. The effects of temperature and concentration have not been systematically investigated for acrylate polymerization although they are known to influence the polymerization of other monomers. ${ }^{5-8}$ The influence of water on the stereochemistry was also studied.

\section{EXPERIMENTAL}

MA and tBA (Wako) were purified in a usual manner and distilled over $\mathrm{CaH}_{2}$ under vacuum immediately before use. The polymerization was carried out in a dry glass ampoule under a dry nitrogen atmosphere. The reaction was initiated by adding $n$-BuLi (heptane solution, conc. $=1.35 \mathrm{M}$ ) to a monomer solution in toluene cooled to a prescribed temperature and was terminated by adding a small amount of methanol. Poly(MA) and poly(tBA) were isolated by precipitation in a large excess of methanol and methanol-water mixture $(4: 1, v / v)$, respectively. Diad ${ }^{9-11}$ and triad ${ }^{12}$ tacticities of the polymers were determined by ${ }^{1} \mathrm{H}$ and ${ }^{13} \mathrm{C}$ NMR measurements, respectively, in $\mathrm{CDCl}_{3}$ with a Varian Gemini 2000 spectrometer (400 $\mathrm{MHz}$ for ${ }^{1} \mathrm{H}, 100 \mathrm{MHz}$ for ${ }^{13} \mathrm{C}$ ).

Other experimental details are the same as those in our previous reports. ${ }^{13,14}$

\section{RESULTS AND DISCUSSION}

\section{Temperature Effect}

The conditions and results of the polymerizations are summarized in Table I. In the MA polymerization, the yield of the $\mathrm{MeOH}$-insoluble polymer decreased as reaction temperature increased, while in the tBA polymerizations, polymer yield was over $90 \%$ at all temperatures. This suggests that some side reactions including the carbonyl attack, which is less likely for tBA having a bulky side group, took place in the MA polymerization similarly to the anionic polymerization of methyl methacrylate. $^{2,15,16}$

The stereostructure of the obtained polymers was investigated using NMR spectroscopy. Diad tacticity of the poly(MA)s was determined by ${ }^{1} \mathrm{H}$ NMR analysis based on the peak splitting of the methylene proton signals $^{9-11}$ (Figure 1), and the same method could be applied for the poly(tBA)s (Figure 2). Under the conditions shown in Table I, MA gave the polymers with higher isotacticity than $\mathrm{BA}$ at all temperatures consisting with the previous reports. ${ }^{17,18}$ In the both MA and tBA

Table I. Anionic polymerization of acrylates in toluene with $n$-BuLi for $24 \mathrm{~h}^{\mathrm{a}}$

\begin{tabular}{|c|c|c|c|c|c|c|}
\hline \multirow{2}{*}{ Run } & \multirow{2}{*}{$\begin{array}{l}\text { Mono- } \\
\text { mer }\end{array}$} & \multirow{2}{*}{$\frac{\text { Temp }}{{ }^{\circ} \mathrm{C}}$} & \multirow{2}{*}{$\frac{\text { Yield }^{\mathrm{b}}}{\%}$} & \multirow{2}{*}{$\frac{M_{n}{ }^{\mathrm{c}}}{\times 10^{4}}$} & \multirow{2}{*}{$M_{w} / M_{n}^{\mathrm{c}}$} & \multirow{2}{*}{$\frac{\text { Tacticity }^{\mathrm{d}}}{m / r}$} \\
\hline & & & & & & \\
\hline 1 & MA & -78 & 66 & 2.02 & 1.84 & $87 / 13$ \\
\hline 2 & MA & -42 & 57 & 2.73 & 2.44 & $90 / 10$ \\
\hline $3^{e}$ & MA & -20 & 18 & 2.99 & 4.30 & $90 / 10$ \\
\hline 4 & MA & -15 & 11 & 2.13 & 1.70 & $90 / 10$ \\
\hline 5 & MA & 0 & 4 & 2.97 & 1.52 & $93 / 7$ \\
\hline 6 & $\mathrm{tBA}$ & -78 & $>99$ & 7.86 & 1.65 & $65 / 35$ \\
\hline 7 & $\mathrm{tBA}$ & -42 & $>99$ & 4.75 & 2.08 & $66 / 34$ \\
\hline 8 & $\mathrm{tBA}$ & -15 & 90 & 1.82 & 4.97 & $71 / 29$ \\
\hline 9 & tBA & 0 & 96 & 1.08 & 3.47 & $71 / 29$ \\
\hline
\end{tabular}

${ }^{\mathrm{a}}[\text { monomer }]_{0}=1.0 \mathrm{M},[n-\mathrm{BuLi}]_{0}=0.05 \mathrm{M} .{ }^{\mathrm{b}} \mathrm{Poly}(\mathrm{MA})$ : methanolinsoluble part; poly(tBA): methanol- $\mathrm{H}_{2} \mathrm{O}(4: 1, \mathrm{v} / \mathrm{v})$-insoluble part. ${ }^{c}$ Determined by GPC with polystyrene standard in THF. ${ }^{\mathrm{d}}$ Determined by $400 \mathrm{MHz}{ }^{1} \mathrm{H} \mathrm{NMR}\left(\mathrm{CDCl}_{3}, 60^{\circ} \mathrm{C}\right)$. ${ }^{\mathrm{e}}$ Polymerization for $3 \mathrm{~h}$.

\footnotetext{
† NEDO fellow (1998-1999). On leave from Institute of Chemistry, Chinese Academy of Sciences, Beijing 100080, P. R. China.

${ }^{+}+$To whom correspondence should be addressed.
} 
polymerizations, isotactic specificity of the polymerization moderately increased with an increase in the polymerization temperature; the difference in meso $(\mathrm{m})$ diad content of the polymers obtained at $-78^{\circ} \mathrm{C}$ and $0^{\circ} \mathrm{C}$ was c a. $6 \%$. This result is similar to that found for the methyl methacrylate (MMA) polymerization in toluene with $n$-BuLi. ${ }^{7}$ A remarkable increase in isotactic specificity based on the raise of reaction temperature has been observed for the polymerization of methyl $\alpha$-ethylacrylate and methyl $\alpha$ - $n$-propylacrylate. ${ }^{7,8}$

It has been reported that the polymerizations of MA at $-78^{\circ} \mathrm{C},-40^{\circ} \mathrm{C}$, and $-20^{\circ} \mathrm{C}$ under very similar conditions to runs 1,2 , and 3 in Table I give the polymers with the $m$ contents of $97 \%, 97 \%$, and $98 \%$, respectively, with the estimated range of error being $\pm 3 \%$, which have been recognized to be the highest values for the MA polymerization using $n$-BuLi. ${ }^{17}$ However, in the previous report, ${ }^{17}$ the $m$ contents may have been overestimated due to relatively low peak resolution of NMR spectra based on the early instrumentations. Thus, the $m$ value of $93 \%$ obtained in run 5 is considered to be the highest isotactic specificity. Although the initiator

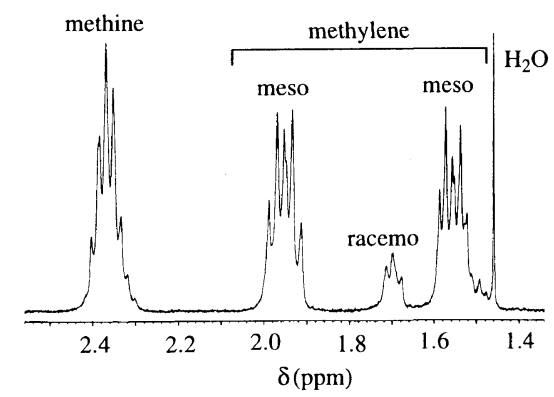

Figure 1. ${ }^{1} \mathrm{H}$ NMR spectrum of poly(MA) (run 3 in Table I) $\left[400 \mathrm{MHz}, \mathrm{CDCl}_{3}, 60 \mathrm{C}, \mathrm{Me}_{4} \mathrm{Si}\right]$.

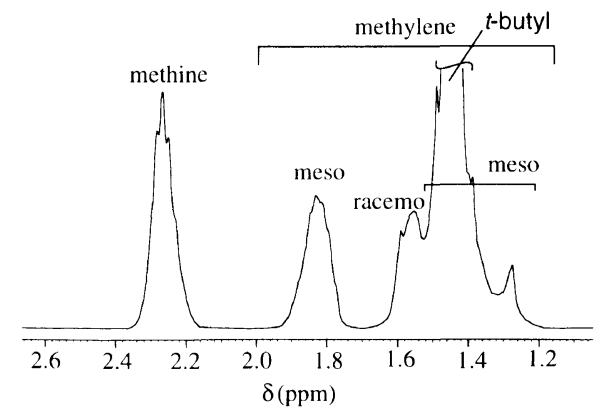

Figure 2. ${ }^{1} \mathrm{H}$ NMR spectrum of poly(tBA) (run 8 in Table I) $\left[400 \mathrm{MHz}^{\mathrm{CDCl}}{ }_{3}, 60 \mathrm{C}, \mathrm{Me}_{4} \mathrm{Si}\right]$.

(A)

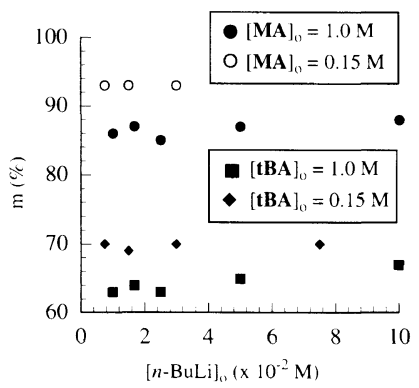

concentration is not clearly shown in the previous report ${ }^{17}$ and may be different from that in our work, it has little effect on the polymerization stereochemistry as the following section of this paper proves.

\section{Effect of $n$-BuLi and Monomer Concentrations}

The effects of initiator concentration on the stereochemistry in the polymerization at $-78^{\circ} \mathrm{C}$ was investigated at constant monomer concentrations $(0.15$ $\mathrm{M}$ and $1.0 \mathrm{M}$ ) by varying $n-\mathrm{BuLi}$ concentration. The $M_{n}$ ranges $v s$. polystyrene standard of the obtained poly(MA)s were $0.25-1.09 \times 10^{4}\left([\mathrm{MA}]_{0}=0.15 \mathrm{M}\right)$ and $2.02-5.32 \times 10^{4}\left([\mathrm{MA}]_{0}=1.0 \mathrm{M}\right)$, and those of the poly $(\mathrm{tBA}) \mathrm{s}$ were $0.98-3.20 \times 10^{4}\left([\mathrm{tBA}]_{0}=0.15 \mathrm{M}\right)$ and $5.85-11.1 \times 10^{4}\left([\mathrm{tBA}]_{0}=1.0 \mathrm{M}\right)$, assuring that the contribution of chain-terminal groups in NMR measurement causing error in tacticity measurement is minimal. The tacticities of the obtained polymers are plotted in Figure 3A. There was no clear dependence of tacticity on the initiator concentration for both of MA and $\mathrm{TBA}$ polymerizations in the range of $[n-\mathrm{BuLi}]_{0}$ used in this work $(0.0075 \mathrm{M}$ to $0.1 \mathrm{M})$.

Effect of monomer concentration on the polymerizations was investigated at a constant $[n-\mathrm{BuLi}]_{0}(0.050 \mathrm{M})$ at $-78^{\circ} \mathrm{C}$. The $M_{n}$ range of the obtained polymers was $2.02-5.93 \times 10^{4}$ for poly(MA) and $1.69-7.86 \times 10^{4}$ for poly(tBA). The tacticities of the polymers are plotted in Figure $3 \mathrm{~B}$, which indicates that isotactic specificity of the polymerization decreases with an increase in the initial concentration of monomers and the effects are more significant in the MA polymerization. The meso diad content of the poly(MA) decreased from $90 \%$ to $67 \%$ as $[\mathrm{MA}]_{0}$ increased from $0.50 \mathrm{M}$ to $5.0 \mathrm{M}$ and that of poly(tBA) also decreased from $69 \%$ to $56 \%$ as $[\mathrm{tBA}]_{0}$ increased from $0.2 \mathrm{M}$ to $5.0 \mathrm{M}$. The effect of monomer concentration may be explained in terms of the change in the polarity of the reaction system. The anionic polymerizations of methacrylates and acrylates in polar solvents are known to lead to a lower isotactic specificity due to the coordination of solvent molecules to growing species. $^{2,4}$ The coordination of plural monomer molecules to a counter cation at a growing end probably reduces the isotactic specific propagation and this should be more pronounced at a higher monomer concentration. Similar effects of monomer concentration have been reported for the MMA polymerization in toluene with $n$-BuLi. ${ }^{5}$

(B)

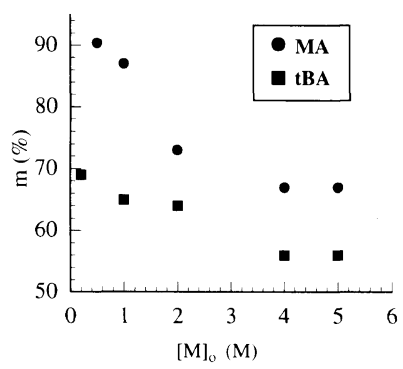

Figure 3. Effects of $n$-BuLi concentration (A) and monomer concentration (B) on the stereochemistry of the polymerization of MA and tBA in toluene at $-78 \mathrm{C}$. Conditions: $[\text { monomer }]_{0}=0.15$ and $1.0 \mathrm{M}$, time $24 \mathrm{~h}(\mathrm{~A}) ;[n-\mathrm{BuLi}]_{0}=0.050 \mathrm{M}$, time $24 \mathrm{~h}(\mathrm{~B})$. 


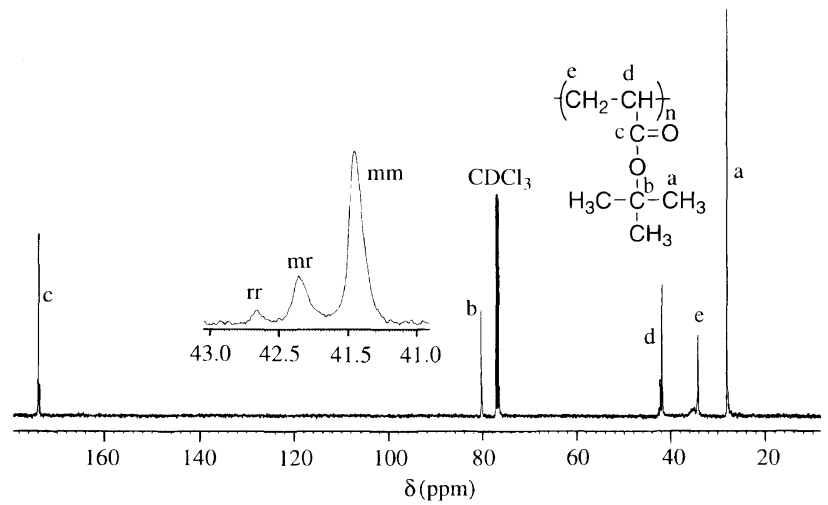

Figure 4. ${ }^{13} \mathrm{C}$ NMR spectrum of poly(tBA) prepared by polymerization in the presence of $\mathrm{LiOH}$ at $0^{\circ} \mathrm{C}$ (acetone-insoluble fraction) $\left[100 \mathrm{MHz}, \mathrm{CDCl}_{3}, 55^{\circ} \mathrm{C}\right]$.

\section{Effect of Water (LiOH Generated In Situ)}

Stereochemistry of the MA and $\mathrm{tBA}$ polymerizations was also affected by the presence of $\mathrm{LiOH}$ generated in situ by adding a small amount of water to the $n$-BuLi solution in heptane $\left(\left[\mathrm{H}_{2} \mathrm{O}\right] /[n-\mathrm{BuLi}]=0.5\right)$. The polymerizations of MA and $\mathrm{tBA}$ were carried out using the $n$-BuLi solution containing LiOH under similar conditions to runs 1,5 , and 8 in Table I. While no clear effect of $\mathrm{LiOH}$ was found in the MA polymerization at $-78^{\circ} \mathrm{C}$, an increase in isotactic specificity was observed in the tBA polymerization $\left[m=70 \%\left(M_{n} 3.71 \times 10^{4}\right)\right.$ and $77 \%$ $\left.\left(M_{n} 3.56 \times 10^{4}\right)\right]$ under the reaction conditions corresponding to runs 5 and 8 in Table I, respectively; the difference in $m$ content caused by $\mathrm{LiOH}$ was $6 \%$ for the tBA polymerization at $0^{\circ} \mathrm{C}$. The acetone-insoluble fraction of the latter poly(tBA) $\left(M_{n} 12.4 \times 10^{4}\right)$ had higher isotacticity than the original sample: $m 85 \%, \mathrm{~mm} / \mathrm{mr} / \mathrm{rr}=$ $74 / 22 / 4$ as indicated by the ${ }^{13} \mathrm{C}$ NMR spectrum (Figure 4). This is the highest diad isotacticity reported for tBA polymerization. ${ }^{19}$ Although the details of the LiOH effect are not immediately known, similar effects have been observed in the polymerization of styrene, ${ }^{20,21} \mathrm{MMA}^{6}{ }^{6}$ ethyl methacrylate, ${ }^{6,7}$ and methyl 2-ethylacrylate. ${ }^{6,8}$

\section{CONCLUSION}

Temperature, monomer concentration, and the presence of $\mathrm{LiOH}$ affected the stereochemistry of the anionic polymerization of $\mathrm{MA}$ and $\mathrm{tBA}$. A higher temperature, a lower monomer concentration, and the presence of LiOH led to the polymers with a higher isotacticity.
Concerning the anionic polymerization of MA and $\mathrm{TBA}$, the effects observed in this work have not been reported although there have been studies ${ }^{17,18}$ on the reaction stereochemistry.

Acknowledgments. This work was supported in part by NEDO for the project on Technology for Novel High-Functional Materials in Industrial Science and Technology Frontier Program, AIST. W.L. thanks NEDO for the fellowship to support his stay at Nagoya University.

\section{REFERENCES AND NOTES}

1. K. Soga and T. Shiono, Prog. Polym. Sci., 22, 1503 (1997).

2. K. Hatada, T. Kitayama, and K. Ute, Prog. Polym. Sci., 13, 189 (1988).

3. T. Nakano and Y. Okamoto, in "Catalysis in Precision Polymerization," S. Kabayashi, Ed., Wiley, Chichester, 1997, pp 268-292.

4. S. Habaue and Y. Okamoto, Kobunshi Kakou (Japanese), 46, 307 (1997).

5. Y. Amerik, W. F. Reynolds, and J. E. Guillet, J. Polym. Sci., A-1, 9, 531 (1971).

6. K. Hatada, Y. Umemura, M. Furomoto, S. Kokan, K. Ohta, and H. Yuki, Makromol. Chem., 178, 1215 (1977).

7. H. Yuki, K. Hatada, T. Niinomi, and K. Miyaji, Polym. J., 1, $130(1970)$.

8. K. Hatada, S. Kokan, T. Niinnomi, K. Miyaji, and H. Yuki, J. Polym. Sci., Polym. Chem., 13, 2117 (1975).

9. T. Suzuki, E. R. Santee Jr., H. J. Harwood, O. Vogl, and T. Tanaka, J. Polym. Sci., Polym. Lett. Ed., 12, 635 (1974).

10. K. Shiohara, S. Habaue, and Y. Okamoto, Polvm. J., 28, 682 (1996).

11. N. A. Porter, T. R. Allen, and R. A. Breyer, J. Am. Chem. Soc., 114, 7676 (1992).

12. M. Suchoparek and J. Spevacek, Macromolecules, 26, 102 (1993).

13. T. Nakano, Y. Okamoto, and K. Hatada, J. Am. Chem. Soc., 114, 1318 (1992).

14. T. Nakano, T. Satoh, and Y. Okamoto, Polym. J., 30, 635 (1998).

15. W. K. Busfield and J. M. Methven, Polymer, 14, 137 (1973).

16. Side reactions involving the $\alpha-\mathrm{H}$ abstraction have also been pointed out: M. Ikeda, T. Hirano, S. Nakayama, and T. Tsuruta, Makromol. Chem., 175, 2775 (1974).

17. K. Matsuzaki, T. Uryu, and A. Ishida, J. Polym. Sci., A-1, 5, 2167 (1967)

18. K. Matsuzaki, T. Uryu, T. Kanai, K. Hosonuma, T. Matsubara, H. Tachikawa, M. Yamada, and S. Okuzono, Makromol. Chem., 178, 11 (1977).

19. A comparable isotacticity has been reported for the polymerization of tBA using a $\mathrm{Zr}$ catalyst: H. Deng and K. Soga, Macromolecules, 29, 1847 (1996).

20. D. J. Worsfold and S. Bywater, Makromol. Chem., 65, 245 (1963).

21. T. Makino and T. E. Hogen-Esch, Polym. Prepr., 38, 164 (1997). 